\title{
EFEKTIFITAS MEDIA ELEKTRONIK DAN MEDIA CETAK TERHADAP PENGETAHUAN HIV/AIDS PADA SISWA SMP NEGERI 4 KOTA TANGERANG
}

\author{
Wasludin \\ Poltekkes Kemenkes Banten \\ Korespondensi:wasludin@poltekkesbanten.ac.id
}

\begin{abstract}
The aim of this research is to know the student's knowledge about HIV/AIDS and the media better and suitable to convey education about HIVIAIDS to the students so as to enhance the knowledge of students about HIV/AIDS. The method of research using experimental design experimental design (pre test - post test controle group design), with respondents grade VIII SMP Negeri 4 Tangerang city as much as 68 people are divided into 2 classes/groups. The results showed, there is a significant difference between the value of knowledge before and after health education carried out by the use of electronic media $(p=0.000)$, there is a significant difference between the value of knowledge before and having done outreach health by using the print media ( $p=$ $0,004)$, and there is a significant difference in the mean of values. Recommended for service related and the edukator health, to increase the knowledge of students in the understanding of a material particularly material health, can use media proper counselling and diverse in order to increase knowledge target.
\end{abstract}

Keywords: HIV/AIDS, electronic media, print media, knowledge

\begin{abstract}
ABSTRAK
Tujuan penelitian ini ingin mengetahui pengetahuan siswa tentang HIV/AIDS dan media yang lebih baik dan cocok untuk menyampaikan edukasi tentang HIV/AIDS kepada siswa sehingga dapat meningkatkan pengetahuan siswa tentang HIV/AIDS. Metoda penelitian menggunakan desain eksperimental dengan rancangan eksperimental ulang (pre test-post test controle group design), dengan responden siswa Kelas VIII SMP Negeri 4 Kota Tangerang sebanyak 68 orang yang terbagi dalam 2 kelas/kelompok. Hasil penelitian menunjukkan, ada perbedaan yang signifikan antara nilai pengetahuan sebelum dan sesudah dilakukan penyuluhan kesehatan dengan menggunakan media elektronik $(\mathrm{p}=0,000)$, ada perbedaan yang signifikan antara nilai pengetahuan sebelum dan sesudah dilakukan penyuluhan kesehatan dengan menggunakan media cetak $(\mathrm{p}=0,004)$, dan ada perbedaan yang signifikan nilai rata-rata pengetahuan antara media elektronik dan media cetak $(\mathrm{p}=0,001)$. Disarankan untuk dinas terkait dan para edukator kesehatan, untuk meningkatkan pengetahuan siswa dalam pemahaman tentang suatu materi khususnya materi kesehatan, dapat menggunakan media penyuluhan yang tepat dan beragam agar dapat meningkatkan pengetahuan sasaran.
\end{abstract}

Kata Kunci: HIV/AIDS, media elektronik, media cetak, pengetahuan 


\section{PENDAHULUAN.}

Berdasarkan data dari Ditjen PP \& PL Kemenkes (2013), angka kejadian HIV/AIDS di Inonesia tahun ke tahun meningkat. Jumlah kasus baru tahun 2011 terdapat 21.031 penderita HIV dan 7.286 AIDS, tahun 2012 terdapat 21.511 penderita HIV dan 8.610 AIDS, dan tahun 2013 terdapat 29.037 penderita HIV dan 5.608 AIDS, sehingga total penderita akhir Desember 2013 sebanyak 179.764 orang yang teridiri dari 127.416 HIV dan 52.348 AIDS dengan jumlah kematian 9.585 orang. Sebagian dari penderita HIV/AIDS tersebut adalah anak remaja umur 15 19 tahun sebanyak 1.710 orang.

Sasaran strategis Kemenkes tahun 2010 - 2014 yaitu menurunnya prevalensi HIV pada penduduk usia 1549 tahun menjadi $<0,5 \%$, meningkatnya persentase penduduk usia 15-24 tahun yang memiliki pengetahuan komprehensif tentang HIV-AIDS dari $65 \%$ menjadi $95 \%$, dan meningkatnya jumlah penduduk usia 15 tahun atau lebih yang menerima konseling dan tes HIV dari 300.000 menjadi 700.000. Kondisi tahun 2011, data-data menunjukan epidemi jalan terus dengan sangat cepat, pengetahuan masyarakat masih rendah, layanan kurang optimal, cakupan masih rendah, dan akses masyarakat terbatas.

Selain memberikan pengetahuan melalui pendidikan, juga dapat dilakukan melalui memberikan informasi kesehatan. Dengan memberikan informasi tentang kebiasaan hidup sehat dan cara pencegahan penyakit diharapkan akan terjadi peningkatan pengetahuan sikap dan perilaku kesehatan dalam diri individu/kelompok sasaran yang berdasarkan kesadaran dan kemauan individu yang bersangkutan, (Notoatmodjo, 2007).

Dalam memberikan pendidikan kesehatan atau informasi kesehatan kepada para siswa atau sasaran dipergunakan berbagai media agar informasi yang disampaikan dapat diterima dan di pahami oleh sasaran sehingga dapat melakukan perilaku yang diharapkan. Dari berbagai media dalam pendidikan kesehatan, media cetak berupa leaflet dan media elektronik berupa vidio merupakan media yang sering digunakan oleh tenaga pendidik atau edukator kesehatan. Untuk mengetahui pengaruh penggunaan kedua media tersebut dan media mana yang cocok dan baik untuk meningkatkan pengetahuan siswa tentang kesehatan 
khususnya HIV/AIDS, peneliti melakukan percobaan manfaat penggunaan kedua media tersebut pada siswa SMP Negeri 4 Kota Tangerang.

Secara umum tujuan penelitian ini ingin mengetahui media yang lebih baik dan cocok untuk menyampaikan edukasi tentang HIV/AIDS kepada siswa sehingga dapat meningkatkan pengetahuan siswa tentang HIV/AIDS

\section{METODE}

Desain penelitian yang digunakan adalah eksperimental dengan pendekatan rancangan eksperimental ulang (pre testpost test controle group design), yaitu subjek dibagi 2 kelompok, pada masingmasing kelompok dilakukan pengukuran sebelum dan sesudah perlakuan yang berbeda.

Karakteristik Sampel dalam penelitian ini adalah responden/siswa kelas VIII pada SMP Negeri 4 Kota Tangerang, baik laki-laki maupun perempuan yang bersedia menjadi responden penelitian. Sedangkan sampel pada penelitian ini diperlukan 68 orang responden yang dibagi menjadi 2 kelompok masing-masing 34 orang responden.

Analisa data yang digunakan dalam penelitian ini adalah analisa univariat yaitu untuk melihat distribusi frekuensi terhadap berbagai karakteristik pada variabel independent dan dependent dengan menggunakan distribusi frekuensi dan persentasi, kemudian dianalisis bivariat untuk melihat hubungan antara variabel independent dengan variavel dependent

\section{HASIL}

\section{Media Elektronik}

\section{Tabel 1}

Distribusi frekuensi nilai pengetahuan responden tentang HIV/AIDS dengan media elektronik

\begin{tabular}{ccccc}
\hline Nilai & Mini & Maks & Mean & Median \\
\hline Sebelum & 45 & 85 & 68,38 & 70.00 \\
\hline Sesudah & 65 & 95 & 83,82 & 90.00 \\
\hline
\end{tabular}

\section{Tabel 2}

Distribusi rata-rata nilai pengetahuan sebelum dan sesudah penyuluhan dengan media elektronik

\begin{tabular}{lcccc}
\hline \multicolumn{1}{c}{ Penilaian } & Mean & SD & $\begin{array}{c}\text { P } \\
\text { value }\end{array}$ & $\mathrm{N}$ \\
\cline { 1 - 3 } Sebelum & 68.38 & 11.724 & 0.000 & 34 \\
${$\cline { 1 - 3 }$} }$ & 83.82 & 10.875 & & 34 \\
\hline
\end{tabular}

\section{Media Cetak}

Tabel 3

Distribusi frekuensi nilai pengetahuan responden tentang HIV/AIDS dengan media cetak

\begin{tabular}{ccccc}
\hline Nilai & Min & Maks & Mean & Median \\
\hline Sebelum & 50 & 90 & 68,53 & 67,50 \\
\hline Sesudah & 65 & 95 & 84,44 & 85,00 \\
\hline
\end{tabular}


Tabel 4

Distribusi rata-rata nilai pengetahuan sebelum dan sesudah penyuluhan dengan media cetak

\begin{tabular}{lcccc}
\hline \multicolumn{1}{c}{ Penilaian } & Mean & SD & P value & N \\
\cline { 1 - 3 } Sebelum & 68.53 & 10.410 & \multirow{2}{*}{0.004} & 34 \\
\cline { 1 - 2 } \cline { 1 - 2 } Setelah & 80.44 & 7.216 & & 34 \\
\hline
\end{tabular}

\section{Media Elektronik dan Media Cetak}

\section{Tabel 5}

Distribusi frekuensi nilai pengetahuan responden tentang HIV/AIDS dengan media elektronik dan cetak

\begin{tabular}{ccccc}
\hline Nilai & Min & Maks & Mean & Median \\
\hline Sebelum & 45 & 90 & 68,46 & 70.00 \\
\hline Sesudah & 65 & 95 & 82,13 & 85.00 \\
\hline
\end{tabular}

Tabel 6

Distribusi nilai pengetahuan responden menurut media penyuluhan

\begin{tabular}{ccccc}
\hline Media & Mean & SD & $\begin{array}{c}\text { P } \\
\text { value }\end{array}$ & $\mathrm{N}$ \\
\cline { 1 - 3 } Elektronik & 76,54 & 10.317 & 0.001 & 34 \\
\cline { 1 - 3 } \cline { 5 - 6 } Cetak & 76,32 & 6.491 & & 34 \\
\hline
\end{tabular}

\section{PEMBAHASAN}

Memperhatikan hasil di atas menunjukkan bahwa ada perbedaan meningkat antara nilai pengetahuan responden antara sebelum dan sesudah penyuluhan baik menggunakan media elektronik maupun menggunakan media cetak. Hal ini sesuai dengan pendapat Bloom dalam Notoatmodjo (2010) bahwa tingkatan pengetahuan pertama yaitu tahu diartikan sebagai mengingat suatu materi yang telah dipelajari sebelumnya. Termasuk kedalam pengetahuan tingkat ini adalah mengingat kembali (recal) sesuatu yang spesifik dari seluruh bahan yang dipelajari atau rangsangan yang telah diterima.

Nilai rata-rata pengetahuan responden dengan mengunakan media elektronik lebih tinggi $(76,54)$ dibandingkan dengan nilai rata-rata pengetahuan responden dengan menggunakan media cetak (76,32). Pengetahuan responden tentang HIV/AIDS sudah termasuk kategori cukup baik karena nilai rata-rata mereka 56 - 75, ini sesuai dengan pendapat Arikunto (2006) dalam Wawan (2010), klasifikasi pengetahuan dalam sebuah penelitian dapat dikategorikan menjadi tiga kategori tingkat pengetahuan, yaitu:

a. Seseorang dikatakan baik jika mampu menjawab 76\% - 100\% dari soal yang disajikan. Berarti orang tersebut mengetahui hal tersebut dengan baik (tahu).

b. Cukup baik jika mampu menjawab $56 \%-75 \%$ dari soal yang disajikan. Berarti orang tersebut cukup mengetahui hal tersebut dengan baik (cukup tahu).

c. Kurang baik jika mampu menjawab $<56 \%$ dari soal yang disajikan. 
Berarti orang tersebut kurang mengetahui hal tersebut dengan baik (kurang tahu).

Responden dapat mengingat kembali pengetahuan yang diperoleh melalui media elektronik dan cetak yang dibuktikan dengan adanya peningkatan rata-rata nilai sebelum dan sesudah penyuluhan walaupun secara individual ada juga responden yang nilai sesudah penyuluhan menurun dibadingkan dengan nilai sebelum mendapatkan penyuluhan, oleh karena itu dapat disimpulkan bahwa secara umum penyuluhan kesehatan dapat meningkatkan pengetahuan responden tentang HIV/AIDS. Hal ini dimungkinkan bahwa responden lebih senang atau tertarik mendengarkan penjelasan dari fasilitator daripada melalui media elektronik atau dengan kata lain bahwa responden lebih senang menerima pengetahuan (disuapi) dari pada mencari sendiri pengetahuan melalui membaca atau diskusi karena responden masih tergolong muda dan sedikit keingin tahuannnya tentang materi yang dibahas. Hal ini sesuai dengan pendapat Nursalam (2003), semakin cukup umur, tingkat kematangan dan kekuatan seseorang akan lebih matang dalam berfikir dan bekerja, makin tua umur seseorang, makin konstruktif dalam menghadapi masalah yang di hadapi.

Soal/pertanyaan untuk mengungkap pengetahuan responden tentang HIV/AIDS meliputi pengertian, penyebab, gejala/tanda, faktor resiko, pencegahan dan aktifitas yang tidak menularkan HIV/AIDS. Hampir seluruh responden menjawab tepat pertanyaan mengenai pengertian, penyebab, dan pencegahan HIV/AIDS, tetapi masih banyak yang menjawab salah tentang cara penularan dan masih ada stigma pada responden bahwa HIV/AIDS merupakan penyakit keturunan atau kutukan sehingga mereka harus diasingkan.

Rata-rata nilai pengetahuan dengan media elektronik adalah 83,82 dengan standar deviasi 10.87, sedangkan ratarata nilai pengetahuan dengan media cetak 80.44 dengan standar deviasi 7,21. Hasil uji statistik diperoleh nilai $\mathrm{p}=$ 0.000 berarti pada alpha 5\% ada perbedaan yang signifikan nilai rata-rata pengetahuan antara media elektronik dan media cetak

Memperhatikan hasil uji statistik terhadap nilai pengetahuan sebelum dan sesudah penyuluhan kesehatan dengan media elektronik diperoleh nilai $\mathrm{p}=$ 
0.000, maka dapat disimpulkan ada perbedaan yang signifikan antara nilai pengetahuan sebelum dan sesudah dilakukan penyuluhan kesehatan dengan menggunakan media elektronik, pada media cetak diperoleh nilai $\mathrm{p}=0.004$, maka dapat disimpulkan ada perbedaan yang signifikan antara nilai pengetahuan sebelum dan sesudah dilakukan penyuluhan kesehatan dengan menggunakan media cetak, dan hasil uji statistik nilai pengetahuan pada media elektronik dan cetak diperoleh nilai $\mathrm{p}=$ 0.001 berarti pada alpha $5 \%$ ada perbedaan yang signifikan nilai rata-rata pengetahuan antara media elektronik dan media cetak

Hipotesis yang diajukan peneliti yaitu, "media elektronik lebih baik daripada media cetak dalam meningkatkan pengetahuan responden tentang HIV/AIDS", namun hasil uji statistik menunjukkan terdapat perbedaan yang signifikan antara media elektronik dan cetak yang menunjukkan bahwa media elektronik lebih baik daripada media cetak $(p=0,001)$. Ini disebabkan karena responden lebih senang mendengarkan penjelasan materi melalui audiovisual $=$ vidio $($ media elektronik) daripada mendapatkan penjelasan melalui ceramah dengan media cetak. Hasil tersebut sesuai juga dengan persyaratan menggunakan media elektronik adalah apabila peserta sudah pernah mendapatkan materi yang di akan dibahas tetapi belum terlalu mendalam memahaminya dan materi yang tepat untuk dividiokan adalah materi yang menarik atau sedang menarik perhatian peserta, sehingga akan mengakibatkan motivasi peserta lebih baik pada diskusi. Selain itu materi HIV/AIDS kemungkinan tidak menarik untuk dibahas lebih dalam melalui melihat vidio sehingga peserta tidak serius melaksanakan belajar, disamping itu waktu yang tersedia untuk diskusipun tidak memadai karena hanya 60 menit.

\section{SIMPULAN}

1. Pengetahuan responden tentang HIV/AIDS meningkat antara sebelum dan sesudah penyuluhan kesehatan baik dengan media elektronik maupun dengan media cetak.

2. Nilai rata-rata pengetahuan dengan media elektronik lebih tinggi dibadingkan dengan nilai rata-rata pengetahuan dengan media cetak.

3. Ada perbedaan yang signifikan antara nilai pengetahuan sebelum dan sesudah dilakukan penyuluhan 
kesehatan dengan menggunakan media elektronik $(\mathrm{p}=0,000)$, ada perbedaan yang signifikan antara nilai pengetahuan sebelum dan sesudah dilakukan penyuluhan kesehatan dengan menggunakan media cetak $(\mathrm{p}=0,004)$, dan ada perbedaan yang signifikan nilai rata-rata pengetahuan antara media elektronik dan media cetak $(\mathrm{p}=0,001)$.

\section{DAFTAR PUSTAKA}

1. Arifah, Siti (2010), Pengaruh pendidikan kesehatan dengan modul dan media audiovisual terhadap tingkat pengetahuan dan sikap wanita dalam menghadapi menoupouse, http:// digilib.uns.ac.id, diakses Juni 2017

2. A Wawan dan Dewi M (2010), Teori Pengukuran Pengetahuan, Sikap, dan Perilaku Manusia, Nuha Medika, Yogyakarta

3. Bertalina, Pengaruh promosi kesehatan terhadap peningkatan pengetahuan tentang gizi seimbang pada siswa SDN di Kecamatan Rajabasa Kota Bandar Lampung

4. Binarti Suhertusi, Desmiwarti, Emi Nurjasmi, (2014), Pengaruh media promosi kesehatan tentang ASI Eksklusif terhadap peningkatan pengatahuan ibu di Wilayah Kerja Puskesmas Lubuk Begalung Padang tahun 2014

5. Depkes RI. 2004 dan 2013. http // Depkes. go. Id
6. Desi Permatasari (2013) Perbedaan pengaruh pendidikan kesehatan menggunakan leaflet dengan audiovisual terhadap tingkat pengetahuan remaja tentang bahaya minuman keras di Desa Wates Simo Boyolali

7. Kumboyono, (2009), perbedaan efek penyuluhan kesehatan menggunakan media cetak dengan media audiovisual terhadap peningkatan pengetahuan pasien Tuberkulosis di Puskesmas Kedungkandang Malang, Jurnal Ilmiah Kesehatan Keperawatan 2014

8. Mansjoer, Arief. 2002. Kapita Selekta Kedokteran. Jakarta, Indonesia

9. Maryunani, A.dkk, 2009. Pencegahan Penularan HIV dari Ibu ke Bayi.Jakarta : Trans Info Media

10. Notoatmodjo, Soekidjo, (2010), Metodologi Penelitian Kesehatan, Jakarta, Rineka Cipta

11. Notoatmodjo, Soekidjo, (2010), Ilmu Perilaku Kesehatan. Jakarta, Rineka Cipta

12. Permatasari, Desi (2013), perbedaan pengaruh pendidikan kesehatan menggunakan leaflet dengan audiovisual terhadap tingkat pengetahuan remaja tentang bahaya minuman keras di desa Wates Simo Boyolali, Jurnal internet diakses Juni 2017

13. Pramudji Ati. Penderita HIV/AIDS.

http://sosbud.kompasiana.com (diakses 30 oktober 2011)

14. Profil Kesehatan Indonesia, 2011

15. Soenar Yully Dewanti. Kasus HIVI

AIDS.http://www.tempointeraktif .com (diakses 26 juli 2011) 
16. Sujarweni, V. (2015), Statistik untuk Kesehatan, Gava Media, Yogyakarta

17. Yustisa, Putu Fanny, dkk (2014), efektifitas penggunaan media cetak dan media elektronik dalam promosi kesehatan terhadap peningkatan pengetahuan dan perubahan sikap siswa SD di Denpasar Bali, Jurnal internet diakses Juni 2017 